\title{
Efecto del pago de la declaración de renta en el sistema cedular Ley 1819 del 2016 en el ahorro y consumo de personas naturales en Florencia, Caquetá (Colombia) ${ }^{1}$
}

\author{
Yelly Yamparli Pardo Rozo ${ }^{2}$ \\ Chris Nathalie Aristizábal Valbuena ${ }^{3}$ \\ Gloria Astrid Duque
}

Recibido: 24 de julio del 2018

Aprobado: 5 de septiembre del 2018

Clasificación JEL: H23, D18

1 Pardo, Y. Y., Aristizábal C. N., y Duque G. A. (2019). Efecto del pago de la declaración de renta en el sistema cedular Ley 1819 de 2016 en el ahorro y consumo de personas naturales en Florencia, Caquetá (Colombia). Revista Activos, 16(31), 113153. DOI: https://doi.org/10.15332/25005278.5318

2 Ph. D. (c) en Ciencias Naturales y Desarrollo Sustentable, magíster en Economía del Ambiente y Recursos Naturales, profesora titular de la Universidad de la Amazonia, investigadora Grupo de estudios de futuro en el mundo amazónico - GEMA, Colombia. Correo electrónico: y.pardo@udla.edu.co - ORCID: https:// orcid.org/0000-0001-8060-0281

3 Magíster en Tributación, profesora de cátedra de la Universidad de la Amazonia, Colombia. Correo electrónico: natha.aristizabal@gmail.com - ORCID: https://orcid. org/0000-0002-7765-8279.

4 Contadora pública, magíster en Ciencias de la Educación, profesora de la Universidad de la Amazonia, investigadora Grupo Sinapsis, Colombia. Correo electrónico: g.duque@udla.edu.co 


\title{
Resumen
}

El estudio identificó el cambio que sufrió en el corto plazo el ahorro y el consumo en las personas naturales contribuyentes en el nuevo sistema cedular, de acuerdo con la Ley 1819 de 2016. Se empleó análisis descriptivo y econométrico para observar el cambio en el ahorro y consumo a través de la propensión marginal al consumo $(\mathrm{PMgC})$ como argumento teórico y matemático. Se encontró que en la situación sin pago de la declaración de renta, la $\mathrm{PMgC}_{1}$ fue de 0.9 en promedio, de modo que por cada $100 \% \mathrm{del}$ ingreso o renta de una persona, esta destina un $90 \%$ al consumo de bienes y servicios y el $10 \%$ restante se supone conforma el potencial de ahorro; en la situación con pago de declaración de renta la $\mathrm{PMgC}_{2}$ fue de 0.95 . El aumento en el gasto por el pago de la declaración de renta puede traducirse como una pérdida en la capacidad de ahorro, consumo o inversión. La población objeto de estudio fueron los profesionales que declararon renta y realizaron pago solo en 2018 del año gravable 2017, quienes se afectaron económicamente con el nuevo sistema tributario, por la reducción del ahorro que estaba destinado a satisfacer necesidades de salud, educación, vivienda, turismo y recreación principalmente.

Palabras clave: propensión marginal al consumo, sistema cedular, efecto tributario, declaración de renta, Ley 1819 de 2016.

\section{Effect of the payment of the income declaration in the system of the Law 1819 of 2016 on the saving and consumption of natural persons in Florencia, Caquetá (Colombia)}

\begin{abstract}
The study identified the change suffered in the short term by the savings and consumption of the natural persons contributing to the new schedular
\end{abstract}


system, in accordance with Law 1819 of 2016. A descriptive and econometric analysis was used to observe the change in savings and consumption through the marginal propensity to consume $(\mathrm{PMgC})$ as a theoretical and mathematical argument. It was found that in the situation without payment of the income statement the PMgC1 was 0.9 on average, so that for every $100 \%$ of income or income of a person, it allocates $90 \%$ to the consumption of goods and services and $10 \%$ is supposed to make up the savings potential; in the situation with payment of income statement the $\mathrm{PMgC} 2$ was 0.95 . The increase in the expense for the payment of the income statement, can be translated as a loss in the capacity of saving, consumption or investment. The population studied was the professionals who declared income and made payment only in 2018 of the taxable year 2017, who were economically affected by the new tax system, by reducing the savings that were destined to satisfy health, education, housing, tourism and recreation mainly.

Keywords: Marginal propensity to consume, schedular system, tax effect, income statement, Law 1819 of 2016.

\section{Introducción}

El impuesto sobre la renta es un tributo que pagan los contribuyentes en Colombia con el propósito de financiar las cargas del Estado con las utilidades anuales. La Ley 1819 del 2016, conocida como la nueva reforma tributaria, creó el nuevo sistema cedular para personas naturales que entró a regir en el año gravable 2017, donde el impuesto se deduce del total de todos los ingresos que puede tener una persona natural, como por ejemplo arrendamientos, pensiones, cesantías, créditos de consumo, etc., además de que se disminuyó el porcentaje de las rentas que anteriormente estaban exentas; esta medida aumentó por un lado el número de personas contribuyentes en el pago de la declaración de renta, y por otro lado incrementó el valor del pago.

Estos marcos normativos afectaron la economía en 2018, siendo Colombia uno de los países que paga más impuestos respecto de otros países 
desarrollados y en vía de desarrollo. Este panorama creó desconcierto en los profesionales afectados económicamente, pues a esto se suma que en la administración pública colombiana han existido altos grados de corrupción e ineficiencia en el gasto público. Sin embargo, esta medida fue adjudicada ante la necesidad del Gobierno para suplir el déficit fiscal y financiar los escenarios de posconflicto.

En Colombia para el 2018, cerca de 2.6 millones de personas declararon renta; pero este panorama donde en el país las oportunidades laborales y el nivel de los salarios son bajos, traerá en el mediano y largo plazo consecuencias negativas en las operaciones de consumo, ahorro y endeudamiento en los hogares de las personas afectadas por la medida.

Teniendo en cuenta la perspectiva microeconómica, un impuesto busca llevar las fuerzas del mercado hacia un equilibrio que garantiza la satisfacción de necesidades mediante los precios y costos que el sistema productivo de una nación puede sostener; esto puede convertirse en una externalidad negativa que afecta directamente los consumos, el ahorro y el nivel de vida de la clase media, situación que puede generar una brecha mayor entre las clases, lo que ocasiona nuevos problemas sociales y mayor inequidad. Ante la situación expuesta, se formuló la siguiente pregunta de investigación: ¿Cómo afectó el pago de la declaración de renta en el ahorro y el consumo de las personas naturales el nuevo sistema cedular de la Ley 1819 de 2016 en Florencia, Caquetá?

Esta investigación determinó los efectos de la reforma tributaria relacionada con la declaración de renta en personas naturales por el año gravable 2017, cuyo pagó se realizó en 2018. Se empleó un análisis descriptivo y herramientas econométricas, fundamentadas en la teoría de la propensión marginal al consumo establecida por Keynes, para estimar el cambio en la situación antes (2017) y después (2018) para los profesionales que en el año actual tuvieron que realizar el pago y sus repercusiones en materia de ahorro y el costo de oportunidad del dinero que se desembolsó para cumplirle al Gobierno. 
Como primer paso se buscó conocer la percepción de los profesionales sobre la medida de política tributaria; como segundo paso se calculó la propensión marginal en el escenario sin impuesto y en el escenario con impuesto para poder cuantificar los cambios y analizar las repercusiones en materia de ahorro, consumos y endeudamiento en los hogares.

Realizar un análisis de los efectos que puede tener una reforma tributaria en uno de los actores como son los hogares, es una herramienta que aporta a la evaluación de la política pública, tributaria y fiscal. Observar sus posibles repercusiones en el mediano y largo plazo, desde variables como el ahorro, el consumo, el endeudamiento y sus implicaciones en las necesidades socioeconómicas, es un punto de partida para fundamentar y argumentar qué tan pertinente y sostenible será la norma en el tiempo. Además permitirá tener en cuenta en próximos estudios la necesidad de instaurar cultura de ahorro e inversión y la adopción de estrategias para mitigar el impacto tanto financiero como económico en los implicados.

\section{Fundamento teórico}

\section{Evolución de las reformas tributarias en Colombia}

Las reformas tributarias más importante cobraron vida a partir de la década de los ochenta cuando la economía colombiana inicia su transición de una economía de sustitución de importaciones hacia el libre comercio que comienza a imperar en Latinoamérica, en la llamada apertura comercial (González y Calderón, 2002). La reforma tributaria de 1986 (Ley 75, 1986) pretendió fortalecer el mercado de capitales y valores para preparar la economía hacia la apertura de los mercados externos, lo que tres años después se concretaría en la creación del Estatuto Tributario de los Impuestos administrados por la Dirección General de Impuestos Nacionales hoy denominada Dian (Dirección de Impuestos y Aduanas Nacionales) (Decreto 624, 1989).

Ya para inicios de la década de los noventa, el Estado buscó reactivar el ahorro y la inversión de la economía (Ley 49, 1990) y así subsanar la 
disminución de los ingresos del Gobierno, ante la reducción de las tasas arancelarias; se introduce una nueva amnistía para la repatriación de capitales en el exterior, en aras de incrementar la inversión y el ahorro en Colombia. Esta amnistía tuvo bastante éxito en su objetivo, sin embargo, también permitió la repatriación de dineros del narcotráfico. Es claro que los incentivos legales se sumaron a una serie de medidas que junto con la estructura económica prevaleciente, incentivaron la tendencia a la revaluación de la tasa de cambio y a un incremento de las tasas de interés (Steiner, 1991).

Ya para la Constitución Política de 1991, se introdujeron grandes reformas al gasto público y se dieron las pautas para culminar el proceso de descentralización, sin embargo, este proceso implicaba una gran responsabilidad de la administración tributaria en el ámbito central, sin que se hiciesen esfuerzos claros a nivel departamental y municipal. Las mayores transferencias a las regiones generaron problemas en las finanzas públicas, pues se tradujeron en gastos desmesurados por parte de estas, generando grandes presiones de recursos a nivel de la nación (Const., 1991).

$\mathrm{Al}$ año siguiente, mediante la Ley 6 (1992), se realizó una nueva reforma tributaria con el fin de garantizar los recursos para financiar los compromisos adquiridos con la Constitución de 1991 e iniciar un programa de inversiones en infraestructura para estimular el proceso de apertura económica. Posteriormente, con la Ley 100 de 1993 que creó el sistema de seguridad social integral, se incrementaron en un $10 \%$ los impuestos a la nómina y se modificó el sistema pensional colombiano; esta situación trajo consigo presiones sobre los ingresos del Gobierno al obligarlo a reconocer parte de las deudas pensionales atrasadas y asumir subsidios a los servicios públicos (Asobancaria, 1999).

Para 1995 surgió la conocida "Ley Páez" (Ley 218, 1995), que pretendía atender la emergencia económica que generó la avalancha sobre el río Páez en el sur de Colombia. Esta buscaba dar impulso a la inversión privada y al crédito en esta zona. Con este fin se otorgaron una serie de beneficios tributarios de carácter nacional, en los que se incluía la exención del impuesto 
de renta por un período de diez años a las nuevas empresas que se crearan en esta región, de la misma manera las utilidades de estas empresas quedarían libres de impuestos. Otro de los beneficios fue el otorgamiento de un crédito fiscal equivalente al $15 \%$ de la inversión realizada y la creación de una zona franca tecnológica.

El mismo año, a partir de la Ley 223 de 1995, por la cual se expidieron normas sobre racionalización tributaria, se buscó incrementar los ingresos para cumplir con los compromisos de gastos impuestos por el Plan Nacional de Desarrollo (salto social), buscando fortalecer los recaudos por medio de mayores sanciones a la evasión y la elusión.

Más tarde, con la Ley 383 de 1997, se establecieron medidas para controlar la evasión, declarando la penalización para los agentes de retención en la fuente y responsables del IVA que eludieran o evadieran el pago del impuesto (Patiño y Torres, 2007).

Luego para 1998, la primera reforma tributaria de la administración del presidente Andrés Pastrana, se aplicó mediante la Ley 488 del mismo año, con la cual definió las competencias del ámbito territorial y nacional en materia de impuestos, pretendiendo incrementar el recaudo de manera que se pudiera aliviar la grave situación de las finanzas públicas.

\section{Impuesto de renta en Colombia y la reforma estructural de la Ley 1819 de 2016}

El impuesto sobre la renta grava todos los ingresos que obtenga un contribuyente en el año que sean susceptibles de producir incremento neto del patrimonio en el momento de su percepción, siempre que no hayan sido expresamente exceptuados, y considerando los costos y gastos en que se incurre para producirlos; es un impuesto de orden nacional, porque tiene cobertura en todo el país y su recaudo está a cargo de la nación; es de tipo directo, porque grava los rendimientos a las rentas del sujeto que responde por su pago ante el Estado. 
La reforma tributaria estructural, Ley 1819 de 2016, que empezó a regir a partir del 1 de enero de 2017, realizó cambios importantes para las personas naturales declarantes del impuesto de renta y complementarios, donde se establece un nuevo sistema cedular para la declaración del impuesto y un nuevo método de depuración de rentas, lo que trajo un aumento en la carga tributaria para el contribuyente.

Esta reforma dejó modificaciones en el impuesto de renta y complementarios, donde se implementó un nuevo método de cálculo denominado sistema cedular, que busca tipificar los ingresos según el origen con el fin de incrementar el recaudo a través del aumento de la base gravable de las personas naturales. El sistema anterior liquidaba las rentas de acuerdo con la clasificación de las personas como empleado, trabajador independiente y otros.

Con este nuevo sistema de cálculo queda eliminado el antiguo método que liquidaba las rentas basado en la tipificación de las personas, tales como, empleado, trabajador independiente y otros y se establece la clasificación por origen del ingreso, de esta manera una persona que obtenga ingresos por varios conceptos o fuentes quedará gravada con cada una de ellas y se le aplicará el régimen cedular al que corresponda, el cual, la reforma tributaria lo divide en: a) rentas de trabajo; b) pensiones; $c$ ) rentas de capital; d) rentas no laborales y, e) dividendos y participaciones (Ley 1819, 2016, art. 1).

Como resultado del sistema cedular para el cálculo de las rentas para personas naturales, se dan dos grandes cambios para el impuesto de renta, uno de ellos es que quedó eliminado el sistema anterior que contemplaba la retención mínima dada por el impuesto mínimo alternativo nacional (IMAN) y el impuesto mínimo alternativo simple (IMAS), y el segundo, que cambia el procedimiento de depuración del tributo, en el que se contempla que los ingresos no constitutivos de renta, deducciones y rentas exentas no podrán exceder del $40 \%$ del total de los ingreso (Ley 1819, 2016, art. 336).

El nuevo método clasifica las rentas así: a) rentas de trabajo; b) pensiones; c) rentas de capital; d) rentas no laborales y, e) dividendos y participaciones. 
Las principales características de la reforma frente a las personas naturales contribuyentes para la declaración de renta son:

i. El sistema cedular. La reforma tributaria del 2016 (Ley 1819) creó un sistema que categoriza los ingresos en cinco grupos: rentas de trabajo, de pensiones, de capital, no laborales y de dividendos; cada una con su esquema de depuración y topes independientes. Al obtener la renta gravable en cada una de ellas, puede implicar un aumento de impuestos; también podría implicar una disminución por ejemplo, los arrendamientos hasta 19 millones de pesos son exentos del pago del impuesto.

ii. Nuevo tratamiento a las cesantías. Antes las cesantías se consideraban un ingreso para el trabajador en el momento que disponía de ellas y, por lo tanto, no eran un ingreso gravable hasta que se las utilizaba. Con la reforma, las cesantías pasaron a ser un ingreso para el trabajador cuando se le trasladan al fondo de cesantías. Y dado que este cambio aplicó a las cesantías pagadas a partir del 2017, el efecto será un mayor ingreso e impuesto de renta.

iii. Mayor tasa a las rentas de capital. Los ingresos por temas como rendimientos financieros y arrendamientos (rentistas de capital) no solo tienen una tasa progresiva y marginal dos puntos mayor que otro tipo de rentas, sino que también se les estableció un límite del $10 \%$ a los costos y gastos imputados que se podrán deducir.

iv. Los ingresos de dividendos no gravados que antes eran exentos ahora tendrán una tasa incremental que va del 0 al $10 \%$. Hasta 18 millones sigue siendo un ingreso no constitutivo de renta, a partir de este tope empezarán a tributar.

Aunque la tabla de retención para las rentas laborales no presentó cambios, se puede evidenciar que para los trabajadores independientes o aquellos que graven rentas no laborales, tuvieron una variación importante en la contribución, pues se estableció la base gravable del impuesto de renta sobre 600 (unidades de valor tributario) UVT, con un $10 \%$ como tarifa, que anteriormente se tributaba a partir de 1.090 UVT.

De igual forma, se especificó la renta máxima que depende de las UVT gravadas a un $35 \%$, que antes tenía una tarifa del $33 \%$. Adicionalmente, la 
reforma limita las rentas exentas para las cédulas no laborales y de capital a tan solo un $10 \%$ sin que este exceda 1.000 UVT, que llevado para el año 2017 estaría en tan solo \$31 859 000. (Zarama y Zarama, 2017, citados en Ladino, 2017). Ver las tarifas para el sistema cedular de rentas (Tabla 1).

Tabla 1. Tarifas renta líquida y de pensiones nuevo sistema cedular

\begin{tabular}{|c|c|c|c|}
\hline \multicolumn{2}{|c|}{ Rangos UVT } & \multirow{2}{*}{$\begin{array}{c}\text { Tarifa } \\
\text { marginal }\end{array}$} & \multirow{2}{*}{ Impuesto } \\
\hline Desde & Hasta & & \\
\hline$>0$ & 1.090 & $0 \%$ & 0 \\
\hline$>1.090$ & 1.700 & $19 \%$ & $\begin{array}{l}\text { (Base gravable en UVT menos } 1.090 \\
\text { UVT) } \times 19 \%\end{array}$ \\
\hline$>1.700$ & 4.100 & $28 \%$ & $\begin{array}{l}\text { (Base gravable en UVT menos } 1.700 \\
\text { UVT) x } 28 \%+116 \text { UVT }\end{array}$ \\
\hline$>4.100$ & $\begin{array}{c}\text { En } \\
\text { adelante }\end{array}$ & $33 \%$ & $\begin{array}{l}\text { (Base gravable en UVT menos } 4.100 \\
\text { UVT) x } 33 \%+788 \text { UVT }\end{array}$ \\
\hline
\end{tabular}

Fuente: Estatuto Tributario Legis (2018).

Se evidencia el aumento en las rentas para personas naturales, porque dado que la tarifa no sufrió variación, se impone el incremento mediante la restricción de los conceptos y del valor que se pueden deducir del impuesto, por lo que los contribuyentes deberán pagar más en anticipos de rentas que lo que venían pagando en años anteriores.

\section{Propensión marginal al consumo para observar el potencial de ahorro y de consumo ${ }^{5}$}

La propensión marginal al consumo $(\mathrm{PMgC})$ puede entenderse como el cambio marginal que sufren los gastos de una población respecto de los cambios que se presentan en los ingresos. Según los planteamientos de esta teoría keynesiana, existe una relación positiva entre el gasto y el ingreso, que puede representarse con la siguiente fórmula:

$$
\text { Gasto }=\beta_{0}+\beta_{1}{ }^{\star} \text { Ingreso Ecuación (1) }
$$

5 Adaptado de Pardo, Peña y Orjuela (2018). 
Donde el parámetro $\beta_{0}$ de la ecuación puede interpretarse como los consumos autónomos o el gasto mínimo que no depende del ingreso. De otro lado, $\beta_{1}$ será el valor de la $\mathrm{PMgC}$, cuyo valor esperado es positivo, para indicar que los aumentos en ingreso, generan incrementos en los gastos, sin embargo, la proporción del aumento en el gasto es menos que proporcional al aumento del ingreso (Vargas, 2015).

Esta proporción del dinero es la que puede destinarse al ahorro, gastos o inversiones. El valor de la PMgC se encuentra entre 0 y 1 . En general, los gastos crecen pero de forma no lineal respecto del ingreso (Roca, 2008). En la Figura 1 se representa lo anteriormente descrito.

Suponiendo una función lineal, se deben tener en cuenta los siguientes supuestos: el consumo depende del ingreso; el gasto aumenta si el ingreso aumenta y finalmente el aumento del ingreso genera posibilidades en otros consumos; este último concepto es llamado como la propensión marginal al consumo (PMgC), donde al ingreso disponible se le deben restar los impuestos. Si los impuestos aumentan, el consumidor lo experimenta como una disminución en los ingresos lo cual traerá cambios en la cantidad de bienes y servicios que tenderán a reducirse y esto afectará finalmente a los productores.

Figura 1. Función de gasto respecto del ingreso

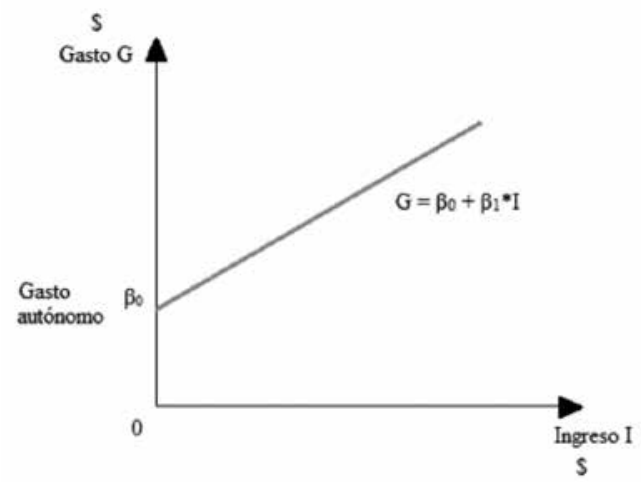

Fuente: Tomado de Pardo, Peña y Orjuela (2018) 
Un impuesto reduce la propensión marginal al consumo, luego el nivel de gastos disminuye lo que tendrá una repercusión en el mercado de bienes y servicios. Ver Figura 2.

Figura 2. Disminución en la propensión marginal al consumo (G a G’)

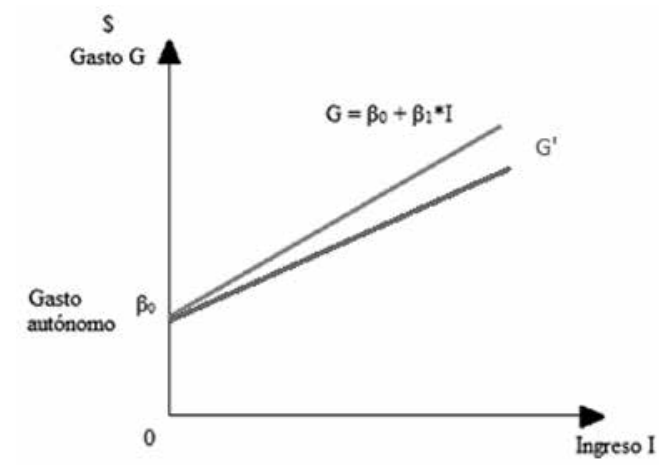

Fuente: elaboración propia.

\section{Métodos}

La presente investigación fue de carácter descriptivo y se sirvió del análisis cualitativo y cuantitativo para evidenciar un fenómeno social a partir de sus rasgos determinantes (Taylor y Bogdan, 1987). La población objeto de estudio fueron los cerca de 14.000 profesionales con los que cuenta el departamento del Caquetá según el Observatorio Laboral con Especialización y Maestría, que para Florencia se estima en cerca del $70 \%$. Debido a la naturaleza contable, financiera y socioeconómica de los datos, su disponibilidad y el grado de dificultad en el acceso a la información, el tipo de muestreo empleado fue por conveniencia (no probabilístico, Hernández, Fernández y Baptista, 2014), donde se tomaron noventa (90) profesionales que al 2018 tuvieron que declarar renta en respuesta a la Ley 1819 del 2016 y que en año 2017 no realizaron pagos o estos fueron muy bajos por este concepto (determinación del impuesto sobre la renta de las personas naturales).

Por ello, las fuentes de información fueron de tipo directo, donde se empleó la técnica de encuesta, dirigida a profesionales de Florencia, 
Caquetá. Esta estuvo conformada por tres bloques de preguntas; en el primero se indagó sobre las características socioeconómicas del encuestado como género, edad, profesión, estado civil, tipo de empleo, personas en la unidad familiar, nivel educativo y años de experiencia, entre otros. En el segundo bloque de preguntas se buscó conocer la información sobre los gastos mensuales, ingresos mensuales, pago por declaración de renta que proviene del formato 208 del 2017 y 210 del 2018, al igual que la fuente y origen del dinero para el pago. El tercer bloque preguntó sobre las expectativas del encuestado frente a la medida tributaria y sus impactos en las necesidades básicas. Se utilizaron preguntas abiertas y cerradas con múltiple respuesta; las preguntas de percepción emplearon para su valoración escalas de Likert. Como información secundaria se usaron los certificados de ingresos y retenciones del 2017 y las declaraciones de renta de los años 2017 y 2018 de los encuestados.

Se empleó un modelo econométrico para estimar una función de gastos versus ingresos para poder establecer la propensión marginal al consumo en la situación antes (sin el pago de la declaración o pago en el 2017) y la situación después (el pago realizado en el 2018). Los modelos matemáticos se describen respectivamente:

$$
\begin{gathered}
\text { Gasto }_{2017}=\beta_{0} \pm \beta_{1} * \text { Ingreso } \pm \beta_{2} * \text { Género } \pm \beta_{3}^{*} \text { Nivel Educativo } \pm \beta_{4} * \\
\text { Experiencia }+\mu
\end{gathered}
$$

Ecuación (2). Modelo empírico 1 situación 2017

$$
\begin{gathered}
\text { Gasto }_{2018}+\text { Pago DR }=\beta_{0} \pm \beta_{1} * \text { Ingreso } \pm \beta_{2} * \text { Género } \pm \beta_{3} * \\
\text { Nivel Educativo } \pm \beta_{4} \star \text { Experiencia }+\mu
\end{gathered}
$$

Ecuación (3). Modelo empírico 2 situación 2018

Donde $\mathrm{G}$ es el gasto; la variable dependiente de carácter continuo dada en pesos colombianos según el gasto anual del encuestado, en la Ecuación (2) es el valor anual; en la Ecuación (3) es el valor anual más el pago de la declaración. Como variables independientes se tienen: 
Ing: el ingreso es una variable independiente de tipo continuo, está dada en pesos colombianos según el ingreso anual.

Ge: el género es una variable dicotómica, que representa el género del profesional encuestado, toma el valor de 1 si se trata del género masculino y el valor de 0 si se trata del género femenino.

NE: la variable educación es una variable independiente, de carácter cualitativo, categórica, que representa el nivel educativo del profesional en la academia: toma el valor de 0 si es especialista, toma el valor de 1 si es magíster, toma el valor de 2 si es doctor.

EC: es el estado civil, variable discreta que toma el valor de 1 si el encuestado tiene cónyuge y toma el valor de 0 si no lo tiene.

Edad: es una variable numérica que representa la edad del encuestado.

$\mu$ : es el nivel de error o la variable aleatoria del modelo.

Para analizar los datos se tendrá en cuenta la metodología econométrica, donde luego de recopilar la información del trabajo de campo (aplicación de encuestas), a través de un modelo econométrico, se validan estadística y teóricamente los modelos matemáticos propuestos conforme al planteamiento teórico fundamentado en análisis microeconómico (Gujarati y Porter, 2010), como se presenta a continuación.

\section{Planteamiento teórico}

Esta investigación tuvo como fundamento metodológico los procedimientos del análisis econométrico, donde se parte del planteamiento de un fundamento teórico que ya se explicó en la revisión de la literatura, teoría keynesiana, donde Keynes establece que la ley psicológica fundamental, consiste en que los hombres, por regla general (en promedio), están dispuestos a incrementar su consumo en la medida que su ingreso aumenta, pero no en la misma cuantía del aumento en su ingreso. Es decir, por un aumento 
generado en el nivel de ingreso, el cambio en el gasto generado será menos que proporcional a este. En términos generales, la propensión marginal al consumo es mayor que cero, pero menor a 1; esto es: $0<\mathrm{PMgC}<1$.

\section{Especificación del modelo matemático de la teoría}

Bajo el supuesto de la existencia de una relación lineal entre X y Y, tenemos que:

$\mathrm{Y}=$ Gasto de consumo, depende de $\mathrm{X}=$ Ingreso y con ello la siguiente ecuación lineal: $Y=\beta_{1}+\beta_{2} X$ con la condición planteada conforme a la teoría: $0<\beta_{2}<1$, donde $\beta_{1}$ = es el intercepto de la recta (punto de corte con el eje $\mathrm{Y}$ ), y es la pendiente, que será interpretada como la PMgC. La Figura 3 presenta esta situación.

Figura 3. Gasto vs. ingreso modelo general

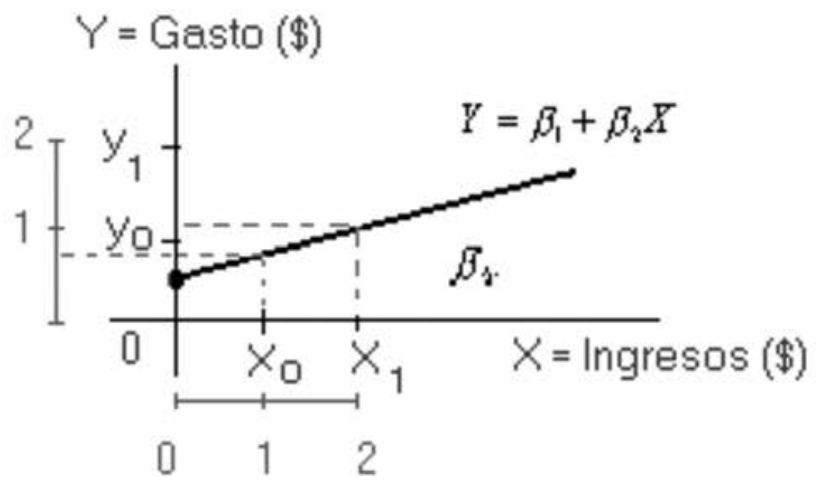

Fuente: Pardo, Peña y Orjuela (2018).

\section{Especificación del modelo econométrico}

En el modelo econométrico se tiene en cuenta que, debido a que se tomará una muestra para corroborar la teoría, entonces se introduce el término de 
error o de perturbación para indicar la holgura del modelo generada por la omisión de variables y otros errores en que se puede incurrir (ver Fórmulas 1 y 2). Se indica $n$ (tamaño de la muestra personas u hogares), el tipo de muestreo (aleatorio simple, estratificado, etc.), y la forma funcional (lineal).

\section{Obtención de datos}

Los datos son de corte transversal (las variables son tomadas en el mismo período de tiempo y espacio). De los hogares de personas naturales se obtienen las variables de gasto e ingreso y otras características descritas en el modelo empírico. Se codifican según su naturaleza continua y dicotómica, dado el caso.

\section{Estimación de los parámetros del modelo econométrico}

Con los datos obtenidos se hallan los parámetros tales como $\hat{\beta}_{i}, \hat{\sigma}, e e\left(\hat{\beta}_{i}\right) R^{2}, F_{c}, t_{c}$ empleando el análisis de regresión mediante el método de mínimos cuadrados ordinarios.

\section{Pruebas de hipótesis}

Para analizar la validez estadística y teórica de los datos y resultados obtenidos, se realizarán pruebas de hipótesis en el modelo hallado. Las pruebas de hipótesis siguen estos pasos: planteamiento de hipótesis (nula Ho y alterna $\mathrm{Ha}$ ); establecimiento del nivel de significancia; elección del estadístico de prueba y, finalmente, la conclusión para observar si se cumple o no la hipótesis. 


\section{Resultados}

\section{Características socioeconómicas de los profesionales encuestados}

La muestra de estudio presentó las siguientes características en materia de género, edad, nivel de ingresos, gastos, nivel educativo, estado civil y la propensión marginal al consumo. Se descartaron 5 de las 90 encuestas, pues tenían datos catalogados como atípicos y datos faltantes. Las Tablas $2,3,4,5,6,7,8,9$ y 10 presentan las condiciones sociales y económicas de los encuestados.

Tabla 2. Género

\begin{tabular}{l|c|c}
\hline \multicolumn{1}{c|}{ Género } & Frecuencia & \% relativo \\
\hline Masculino & 43 & 50.6 \\
\hline Femenino & 42 & 49.4 \\
\hline Total & 85 & 100.0 \\
\hline
\end{tabular}

Fuente: elaboración propia.

La Tabla 2 presenta el género de los profesionales encuestados. Se observa que el $50.6 \%$ son personas del género masculino y el $49.4 \%$ son del género femenino.

Tabla 3. Edad en años

\begin{tabular}{l|c|c}
\multicolumn{1}{c|}{ Edad } & Frecuencia & \% relativo \\
\hline 30 a 40 años & 22 & 25.9 \\
\hline 41 a 50 años & 20 & 23.5 \\
\hline 51 a 60 años & 23 & 27.1 \\
\hline Mayor a 60 años & 20 & 23.5 \\
\hline Total & 85 & 100.0 \\
\hline
\end{tabular}

Fuente: elaboración propia. 
130 ACTIVOS | Yelly Yamparli Pardo Rozo, Chris Nathalie Aristizábal Valbuena, Gloria Astrid Duque

La Tabla 3 presenta la edad de los profesionales encuestados. Se observa que es casi proporcional la cantidad en el rango de edad.

Tabla 4. Educación del encuestado

\begin{tabular}{l|c|c}
\hline Estudios & Frecuencia & \% relativo \\
\hline Profesional & 22 & 25.9 \\
\hline Especialización & 22 & 25.9 \\
\hline Maestría & 34 & 40.0 \\
\hline Doctorado & 7 & 8.2 \\
\hline Total & 85 & 100.0 \\
\hline
\end{tabular}

Fuente: elaboración propia.

La Tabla 4 deja entrever que un $40 \%$ son magísteres, y profesionales en un $25.9 \%$ y especialistas en igual proporción. Solo un $8.2 \%$ son doctores.

Tabla 5. Estado civil

\begin{tabular}{l|c|c}
\hline Estado civil & Frecuencia & \% relativo \\
\hline Con cónyuge & 70 & 82.4 \\
\hline Sin cónyuge & 15 & 17.6 \\
\hline Total & 85 & 100.0 \\
\hline
\end{tabular}

Fuente: elaboración propia.

La Tabla 5 se refiere al estado de convivencia del profesional; esto es casado o en unión libre el $82.4 \%$ y solteros, separados o viudos el $17.6 \%$.

Tabla 6. Renta líquida anual del encuestado

\begin{tabular}{l|c|c}
\hline Renta líquida anual & Frecuencia & \% relativo \\
\hline 44 a 60 millones & 33 & 38.9 \\
\hline 61 a 75 millones & 17 & 20.0 \\
\hline 76 a 90 millones & 15 & 17.6 \\
\hline 91 a 105 millones & 8 & 9.4 \\
\hline Mayor a 105 millones & 12 & 14.1 \\
\hline Total & 85 & 100 \\
\hline
\end{tabular}

Fuente: elaboración propia. 
La Tabla 6 presenta la renta líquida, que es el valor del ingreso anual del encuestado. Se destacan valores como el $38.8 \%$ con renta anual entre 44 a 60 millones, un $20 \%$ entre 61 a 75 millones y un $17.6 \%$ con rentas anuales entre 76 a 90 millones. Solo un $14.1 \%$ con ingreso anual superior a los 105 millones. La Tabla 7 expone parámetros asociados al ingreso y gasto anual.

Tabla 7. Algunos parámetros de las variables continuas ingreso y gasto anual

\begin{tabular}{l|c|c}
\hline Medida & Ingreso anual \$ & Gasto anual \$ \\
\hline Promedio & 70862011 & 63842623 \\
\hline Mínimo & 20949000 & 3159700 \\
\hline Máximo & 131442000 & 130127580 \\
\hline Desviación estándar & 24941574 & 23665331 \\
\hline
\end{tabular}

Fuente: elaboración propia.

El promedio del ingreso es de $\$ 70.862$ millones y $\$ 63.842$ millones para el gasto. La desviación estándar de $\$ 24.941$ millones sugiere que el 60 por ciento de los datos se concentra en ingresos de entre $\$ 45.9$ millones y $\$ 95.8$ millones. De otro lado, la Tabla 8 presenta la condición laboral del empleado y el sector al que pertenece.

Tabla 8. Condición laboral

\begin{tabular}{l|c|c}
\hline Situación laboral & Frecuencia & \% relativo \\
\hline Empleados & 67 & 78.8 \\
\hline Independiente & 18 & 21.2 \\
\hline Total & 85 & 100.0 \\
\hline
\end{tabular}

Fuente: elaboración propia.

El $78.8 \%$ de los encuestados son empleados y el $21.2 \%$ son independientes. De los empleados el $91 \%$ son del sector público y el $9 \%$ son del sector privado. De los encuestados que en un $100 \%$ tuvieron que declarar renta, el $51.8 \%$ tuvieron que realizar pagos en el 2018 (ver Tabla 9 ). De estos el $24.7 \%$ había pagado en 2016 (ver Tabla 10), lo cual permite inferir que se duplicó el recaudo en cuanto al número de personas. El $78.3 \%$ de 
los encuestados no conocía la Ley 1819 del 2018 y el 21.7 \% solo sabía que había una reforma tributaria. Ante esto el $100 \%$ de los declarantes no planificaron el pago. El promedio del valor del pago de la declaración de renta fue de $\$ 2012800$, con un valor mínimo de $\$ 150000$ y un valor máximo de $\$ 19000$ 000. Ahora se presenta de manera comparativa cómo se afectó la propensión marginal al consumo de las personas que tuvieron que pagar versus quienes no tuvieron que hacerlo.

Tabla 9. Profesionales que pagaron declaración de renta año gravable 2017

\begin{tabular}{l|c|c}
\hline Pagó declaración 2017 & Frecuencia & \% relativo \\
\hline $\mathrm{Si}$ & 44 & 51.8 \\
\hline $\mathrm{No}$ & 41 & 48.2 \\
\hline Total & 85 & 100.0 \\
\hline
\end{tabular}

Fuente: elaboración propia.

Tabla 10. Profesionales que pagaron declaración de renta año gravable 2016

\begin{tabular}{|l|c|c|}
\hline Pagó declaración 2016 & Frecuencia & \% relativo \\
\hline $\mathrm{Si}$ & 21 & 24.7 \\
$\mathrm{No}$ & 64 & 75.3 \\
\hline Total & 85 & 100.0 \\
\hline
\end{tabular}

Fuente: elaboración propia.

\section{Determinación de la propensión marginal al consumo}

Se realizó un modelo lineal para hallar la propensión marginal al consumo en la situación sin pago (modelo 1), esto es: Gasto $=\mathrm{a}+\mathrm{b}^{\star}$ Ingreso. Esto arrojó los resultados presentados en la Tabla 11, la cuale tienen un primer segmento que corresponde a las estadísticas de la regresión; una segunda parte que corresponde al cálculo de la tabla Anova que calcula el valor $\mathrm{F}$ Fisher; y una tercera parte de la tabla que presenta los coeficientes, los valores de la t-student, y el p-value. 
Tabla 11. Resultados modelo 1, G vs. todas las variables, en regresión lineal simple.

\begin{tabular}{|c|c|c|c|c|c|c|}
\hline \multicolumn{5}{|c|}{ Estadísticas de la regresión } & & \\
\hline \multicolumn{3}{|c|}{ Coeficiente de correlación múltiple } & \multicolumn{4}{|c|}{0,966176311} \\
\hline \multicolumn{3}{|c|}{ Coeficiente de determinación $\mathrm{R}^{\wedge} 2$} & \multicolumn{4}{|c|}{0,933496663} \\
\hline \multicolumn{3}{|l|}{$\mathrm{R}^{\wedge} 2$ ajustado } & \multicolumn{4}{|c|}{0,927450905} \\
\hline \multicolumn{3}{|l|}{ Error típico } & \multicolumn{4}{|c|}{6097171,92} \\
\hline \multicolumn{3}{|c|}{ Observaciones } & \multicolumn{2}{|c|}{85} & & \\
\hline ANOVA & $\begin{array}{c}\text { Grados de } \\
\text { libertad }\end{array}$ & \multicolumn{2}{|c|}{$\begin{array}{l}\text { Suma de } \\
\text { cuadrados }\end{array}$} & $\begin{array}{l}\text { Promedio } \\
\text { cuadrados }\end{array}$ & $F$ & $\begin{array}{c}\text { Valor } \\
\text { crítico } \\
\text { de F }\end{array}$ \\
\hline Regresión & 7 & \multicolumn{2}{|c|}{$4,0181 \mathrm{E}+16$} & $5,7401 \mathrm{E}+15$ & 154,405234 & $1,25 \mathrm{E}-42$ \\
\hline Residuos & 77 & \multicolumn{2}{|c|}{$2,8625 \mathrm{E}+15$} & $3,7176 \mathrm{E}+13$ & & \\
\hline \multirow[t]{2}{*}{ Total } & 84 & \multicolumn{2}{|c|}{$4,3043 \mathrm{E}+16$} & & & \\
\hline & Coeficientes & \multicolumn{2}{|c|}{ Error típico } & Estadístico $t$ & Probabilidad & \\
\hline Intercepción & 2097816,637 & \multicolumn{2}{|c|}{4395035,41} & 0,47731507 & 0,63448984 & \\
\hline Ingreso & 0,819015277 & \multicolumn{2}{|c|}{0,05080512} & 16,120724 & $2,1589 \mathrm{E}-26$ & \\
\hline Pago & 0,972192596 & \multicolumn{2}{|c|}{0,33124155} & 2,93499593 & 0,00439455 & \\
\hline EC & 149143,2994 & \multicolumn{2}{|c|}{1756152,21} & 0,08492618 & 0,93254051 & \\
\hline Declara & $-3178189,744$ & \multicolumn{2}{|c|}{2267478,57} & $-1,40164048$ & 0,16504074 & \\
\hline Genero & 32322,08536 & \multicolumn{2}{|c|}{1406071,64} & 0,02298751 & 0,9817197 & \\
\hline $\mathrm{NE}$ & 1094157,294 & \multicolumn{2}{|c|}{1054632,86} & 1,03747696 & 0,30276071 & \\
\hline Edad & 42989,73884 & \multicolumn{2}{|c|}{66847,8373} & 0,64309842 & 0,52207081 & \\
\hline
\end{tabular}

Fuente: elaboración propia con programa Excel.

En la Tabla 11 se observa que las variables relevantes estadísticamente (a un $95 \%$ de nivel de confianza), de acuerdo con el valor del t-student y el p-value fueron: el monto del pago y el ingreso. Por ello, se realiza una nueva regresión de gastos versus ingresos y el valor del monto de la declaración de renta, pero esta última variable no es estadísticamente significativa, es decir, que no explica al valor del gasto. Se realiza un nuevo modelo presentado en la Tabla 12, donde se observa el modelo simple, planteado como el 
134 ACTIVOS | Yelly Yamparli Pardo Rozo, Chris Nathalie Aristizábal Valbuena, Gloria Astrid Duque

modelo inicial de gastos versus ingresos, el cual es altamente significativo. Teóricamente, esto es un comportamiento esperado.

Tabla 12. Resultados modelo 1 empleando variables significativas en Tabla 11

\begin{tabular}{|l|c|}
\hline \multicolumn{2}{|l|}{ Estadísticas de la regresión } \\
\hline Coeficiente de correlación múltiple & 0,9948945 \\
\hline Coeficiente de determinación $\mathrm{R} \wedge 2$ & 0,98981507 \\
\hline $\mathrm{R} \wedge 2$ ajustado & 0,97791031 \\
\hline Error típico & 6907300,06 \\
\hline Observaciones & 85 \\
\hline
\end{tabular}

\begin{tabular}{l|c|c|c|c|c}
\hline Anova & $\begin{array}{c}\text { Grados de } \\
\text { libertad }\end{array}$ & $\begin{array}{c}\text { Suma de } \\
\text { cuadrados }\end{array}$ & $\begin{array}{c}\text { Promedio } \\
\text { cuadrados }\end{array}$ & $F$ & $\begin{array}{c}\text { Valor crítico } \\
\text { de } F\end{array}$ \\
\hline Regresión & 1 & $3,89486 \mathrm{E}+17$ & $3,89486 \mathrm{E}+17$ & 8163,48088 & $1,1477 \mathrm{E}-84$ \\
\hline Residuos & 84 & $4,00771 \mathrm{E}+15$ & $4,77108 \mathrm{E}+13$ & & \\
\hline Total & 85 & $3,93494 \mathrm{E}+17$ & & & \\
\hline & Coeficientes & Error típico & Estadístico t & Probabilidad & \\
\hline Ingreso & & & & & \\
\hline Anual & 0,90166208 & 0,009979439 & 90,35198327 & $1,8833 \mathrm{E}-85$ & \\
\hline
\end{tabular}

Fuente: elaboración propia con cálculos en programa Excel.

Los datos permitieron construir la curva de gastos en función de los ingresos de la siguiente forma:

$$
\text { Gastos estimados }=0,90166^{\star} \text { Ingreso } \quad \text { Ecuación (4) }
$$

Partiendo de un comportamiento lineal, esto quiere decir que la propensión marginal al consumo es la derivada o el cambio marginal de esta ecuación, con un valor de 0,90 . El parámetro $\boldsymbol{a}$ es igual a cero porque estadísticamente no fue relevante según la prueba t-student.

Mientras que la variable ingreso sí se demostró que fue estadísticamente válida al realizar la prueba de hipótesis de parcialidad (usando el estadístico t-student y según la bondad de ajuste del $\mathrm{R}^{2}$; este último indica que el 97 
$\%$ de los datos se ajustan al modelo estimado, con lo que permite realizar pronósticos con resultados consistentes). Una PMgC de 0,90 quiere decir que por cada $\$ 1000$ pesos que se incremente el salario de la persona (en el promedio), se generan gastos en $\$ 900$ pesos.

Lo anterior es acorde con la teoría de Keynes pues el valor esperado para la $\mathrm{PMgC}$ está entre 0 y 1 en términos proporcionales; de cada peso que ingresa se gastan $\$ 0,9$. Se puede pensar que los $\$ 0,1$ pesos restantes son dineros que quedarán disponibles para el ahorro, la inversión, o necesidades básicas del individuo y su familia en salud, educación, vivienda, esparcimiento, compra de inmuebles o muebles, entre otros usos al dinero.

Este sería el panorama para las personas en un año normal sin el pago de la declaración. Variables como el género, la edad, el estado civil y el nivel educativo no fueron determinantes desde el punto de vista estadístico en la variable gasto anual. La Figura 4 muestra el comportamiento de los datos y la línea de tendencia en la situación sin pago.

Figura 4. Gastos anuales vs. ingresos anuales

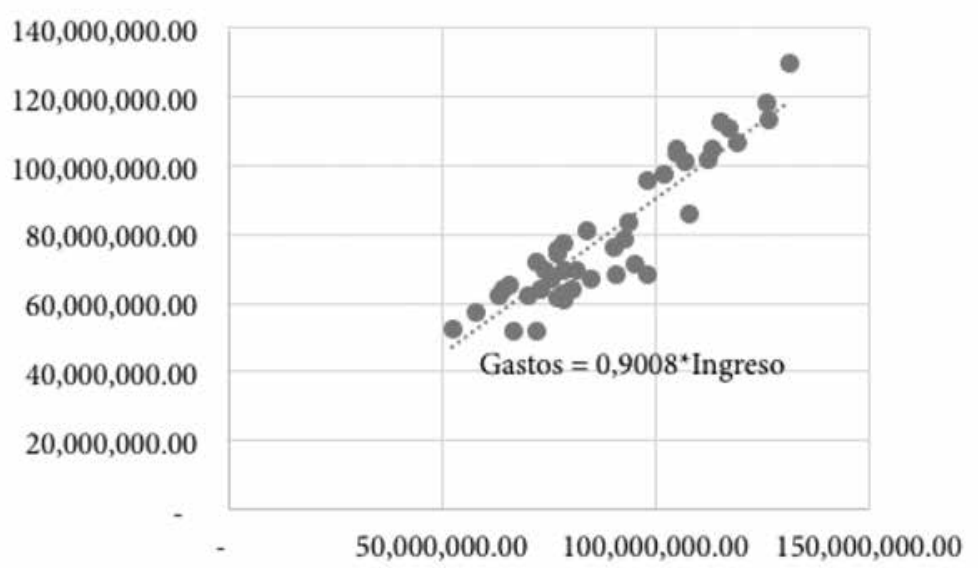

Fuente: elaboración propia con programa Excel. 
136 ACTIVOS | Yelly Yamparli Pardo Rozo, Chris Nathalie Aristizábal Valbuena, Gloria Astrid Duque

Efectos de la reducción de las rentas exentas en el cambio de la $\mathrm{PMgC}$

Para saber si esta $\mathrm{PMgC}$ se ve afectada por la medida tributaria en los hogares de los profesionales, ahora se realiza el mismo ejercicio pero de forma individual de los que declaran pero no pagan, versus los que declaran y pagan de acuerdo con la Ley 1819 del 2018. Se le suma a los gastos anuales el valor del pago realizado en el 2018 (modelo 2).

La Tabla 13 presenta los resultados empleando el programa Excel en la herramienta análisis de regresión.

Tabla 13. Gastos vs. ingresos para los profesionales que pagan declaración

\begin{tabular}{|c|c|c|c|c|c|c|}
\hline \multicolumn{5}{|c|}{ Estadísticas de la regresión } & & \\
\hline \multicolumn{3}{|c|}{ Coeficiente de correlación múltiple } & \multicolumn{2}{|c|}{0,99454579} & & \\
\hline \multicolumn{3}{|c|}{ Coeficiente de determinación $\mathrm{R} \wedge 2$} & \multicolumn{2}{|c|}{0,98912132} & & \\
\hline \multicolumn{3}{|c|}{$\mathrm{R}^{\wedge} 2$ ajustado } & \multicolumn{2}{|c|}{0,96586551} & & \\
\hline \multicolumn{3}{|c|}{ Error típico } & \multicolumn{2}{|c|}{9135176,55} & & \\
\hline \multicolumn{3}{|c|}{ Observaciones } & \multicolumn{2}{|r|}{44} & & \\
\hline & $\begin{array}{l}\text { Grados de } \\
\text { libertad }\end{array}$ & \multicolumn{2}{|c|}{$\begin{array}{c}\text { Suma de } \\
\text { cuadrados }\end{array}$} & $\begin{array}{l}\text { Promedio } \\
\text { cuadrados }\end{array}$ & $\mathrm{F}$ & $\begin{array}{c}\text { Valor crítico } \\
\text { de F }\end{array}$ \\
\hline Regresión & 1 & \multicolumn{2}{|c|}{$3,26269 \mathrm{E}+17$} & $3,26269 \mathrm{E}+17$ & 3909,68557 & $4,4233 \mathrm{E}-43$ \\
\hline Residuos & 43 & \multicolumn{2}{|c|}{$3,58841 \mathrm{E}+15$} & $8,34515 \mathrm{E}+13$ & & \\
\hline \multirow[t]{2}{*}{ Total } & 44 & \multicolumn{2}{|c|}{$3,29857 \mathrm{E}+17$} & & & \\
\hline & Coeficientes & \multicolumn{2}{|c|}{ Error típico } & Estadístico $t$ & Probabilidad & \\
\hline $\begin{array}{l}\text { Ingreso } \\
\text { anual }\end{array}$ & 0,94728472 & \multicolumn{2}{|c|}{0,015149895} & 62,52747851 & $7,436 \mathrm{E}-44$ & \\
\hline
\end{tabular}

Fuente: elaboración propia con programa Excel.

La PMgC está afectada por una tasa de impuestos que puede disminuir su valor significativamente. En los resultados del modelo lineal, La propensión marginal al consumo fue de $\$ 0,9472$, lo cual puede interpretarse desde el punto de vista marginal que por cada $\$ 1000$ pesos se gastan $\$ 947,2$. Esto indica que solo quedarían disponible para el ahorro $\$ 52,8$ pesos por 
cada $\$ 1000$ pesos. Respecto de la situación inicial, el ahorro se redujo en $\$ 47,2$ pesos.

Los datos tienen validez estadística según prueba de hipótesis y el valor del $\mathrm{R}^{2}$. Sin embargo, la tendencia en el total de la población (si la medida tributaria llegara a extenderse al total de los profesionales), el efecto sería el siguiente (ver Tabla 14):

Tabla 14. Resultados modelo 2 en el hipotético de afectarse toda la población

\begin{tabular}{|c|c|c|c|c|}
\hline \multicolumn{3}{|c|}{ Estadísticas de la regresión } & & \\
\hline \multicolumn{2}{|c|}{ Coeficiente de correlación múltiple } & 0,993943 & & \\
\hline \multicolumn{2}{|c|}{ Coeficiente de determinación $\mathrm{R}^{\wedge} 2$} & 0,98792268 & & \\
\hline \multicolumn{2}{|l|}{$\mathrm{R}^{\wedge} 2$ ajustado } & 0,97601792 & & \\
\hline \multicolumn{2}{|l|}{ Error típico } & 7823433,71 & & \\
\hline \multicolumn{2}{|l|}{ Observaciones } & 85 & & \\
\hline & Coeficientes & Error típico & Estadístico t & Probabilidad \\
\hline Ingreso anual & 0,9989433 & 0,0336663 & 29,6719065 & $5,9365 \mathrm{E}-46$ \\
\hline
\end{tabular}

Fuente: elaboración propia con programa Excel.

La PMgC para el ingreso disponible es mucho menor en este caso, cuando se introduce el impuesto por parte del Gobierno. Ahora el nuevo valor de la $\mathrm{PMgC}$ en el modelo 2 fue de $\$ 0,99$. Esto quiere decir que por cada $\$ 1000$ que se tienen de los ingresos, $\$ 999$ son destinados al gasto, por lo que la capacidad de ahorro de los hogares se ha visto afectada. Los datos tienen validez estadística según prueba de hipótesis y el valor del $\mathrm{R}^{2}$.

El cambio en la PMgC alcanzaría 9 pesos por cada $\$ 10$, lo cual puede evidenciar que sin la medida tributaria los hogares de los profesionales contaban con un ahorro de $\$ 100$ pesos por cada $\$ 1000$; ahora el ahorro es de $\$ 1$ peso por cada $\$ 1000$ pesos, lo cual es altamente significativo, si se tiene en cuenta que en países latinoamericanos solo el 20 \% de la población tienen una cultura de ahorro, la cual es más baja frente a países asiáticos pero más alta que los africanos (BID, 2016). La Figura 5 presenta el comportamiento. 
138 ACTIVOS | Yelly Yamparli Pardo Rozo, Chris Nathalie Aristizábal Valbuena, Gloria Astrid Duque

Figura 5. Gastos con pago de declaración vs. ingresos

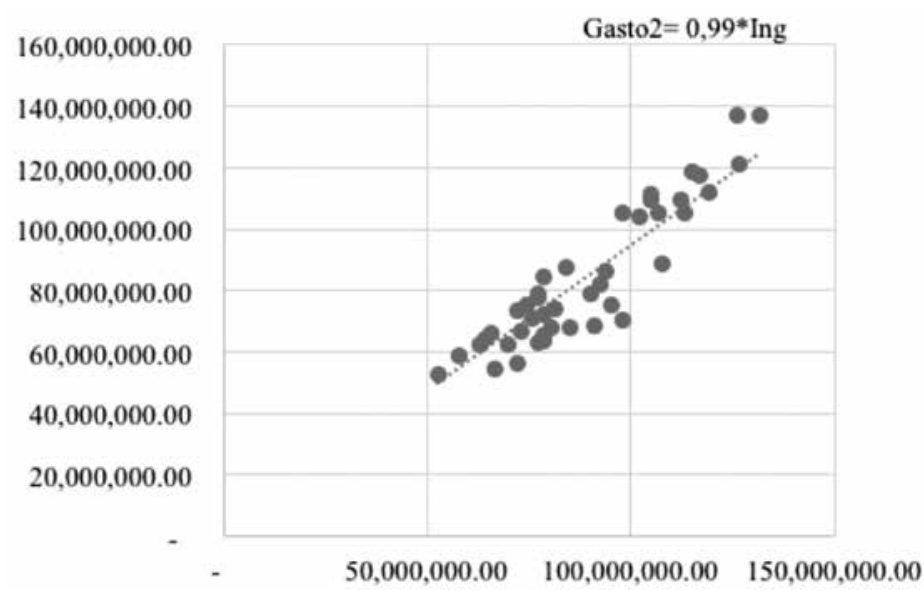

Fuente: elaboración propia con programa Excel.

Para observar de manera comparativa, la Figura 6 presenta los comportamientos en el gasto en la situación con y sin pago de la declaración de manera simultánea.

Figura 6. Cambio en la propensión marginal al consumo por la disminución de las rentas exentas

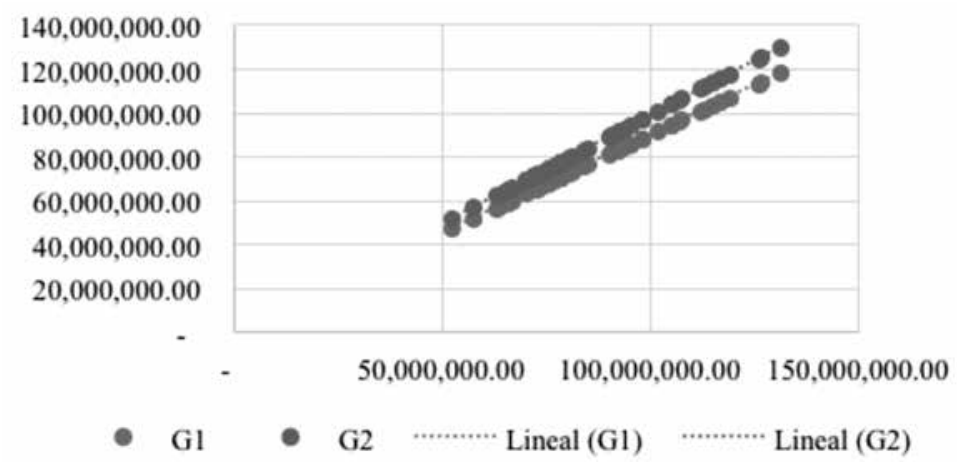

Fuente: Elaboración propia con programa Excel 
En la Figura 6 se observa un "barrido" en contra de las manecillas del reloj, de la pendiente de la curva G1 (gastos anuales del profesional sin pago de la declaración de renta) hacia arriba G2 (gastos anuales con pagos), donde los gastos aumentan pero no el ingreso.

Solo el $33.7 \%$ de los encuestados afirmó que ahorra frente a un $66.3 \%$ que no ahorra. Sin embargo, cuando se preguntó sobre la forma en la que se afectan los ahorros el $44.3 \%$ dijo que de forma media, el $30.7 \%$ que de forma alta y el $25.0 \%$ manifestó que se afectan en muy alto grado. Luego, en cuanto a consumo el $79.5 \%$ manifestó que se afectó en nivel muy alto y el porcentaje restante en nivel alto.

De otro lado, se consideraron los efectos de la medida tributaria tales como la fuente del dinero para el pago de la declaración y las implicaciones en los estadios de la vida en el corto plazo que tenían previstos para destinar dicho dinero, y que se verán afectados de forma económica y financiera. La Tabla 15 presenta la fuente del dinero que se utilizó para pagar la declaración de renta.

Tabla 15. Fuente del dinero para el pago de la declaración

\begin{tabular}{l|c|c}
\hline Fuente & Frecuencia & \% relativo \\
\hline Ahorros & 18 & 40.9 \\
\hline Préstamo & 21 & 47.7 \\
\hline Cesantías & 5 & 11.4 \\
\hline Total & 44 & 100.0 \\
\hline
\end{tabular}

Fuente: elaboración propia con programa Excel.

El $47.7 \%$ empleó préstamos de libre inversión y tarjetas de crédito para poder cumplir con el pago; el $40.9 \%$ utilizó ahorros y un $11.4 \%$ dispuso de una parte de sus cesantías.

Con esto se puede afirmar que además de los intereses que se generan por los préstamos realizados, se afecta el costo de oportunidad de uso del dinero en las prioridades de los hogares tales como salud, vivienda, educación, 
viajes y otros, los cuales deberían tomarse en cuenta como impactos en el sector productivo, es decir, en el mediano y largo plazo.

Al profesional se le indagó sobre sus principales necesidades y el destino de sus ahorros. En la Tabla 16 se exponen las principales necesidades en el corto plazo que se verán afectadas por el pago de la declaración en el 2018 y que ya se tenían presupuestadas para suplir necesidades tanto básicas como suntuarias.

Tabla 16. Principal estadio afectado en el corto plazo

\begin{tabular}{l|c|c}
\hline Estadio & Frecuencia & \% relativo \\
\hline Salud & 25 & 29.4 \\
\hline Transporte & 10 & 11.8 \\
\hline Vivienda & 17 & 20.0 \\
\hline Educación & 15 & 17.6 \\
\hline Recreación & 18 & 21.2 \\
\hline Total & 85 & 100.0 \\
\hline
\end{tabular}

Fuente: elaboración propia con programa Excel.

Se observó que en el corto plazo el $29.4 \%$ de las personas tenían previsto costos en salud (59\% correctiva y $41 \%$ preventiva), seguido de un $21.2 \%$ de los encuestados que tenían previsto actividades de recreación y esparcimiento (el $78 \%$ viajes y un $22 \%$ compras); un $20 \%$ esperaban mejorar las condiciones de vivienda (arreglos y mantenimientos) y un $17.6 \%$ consideraron que se ven afectados aspectos económicos frente a la educación (ahorros programados para educación de sus hijos, familiares y educación propia). Un 11.8 \% se ve afectado en el mejoramiento de sus condiciones de transporte. 
En el agregado de la muestra de estudio se pueden cuantificar los siguientes efectos, según la Tabla 17.

Tabla 17. Efecto promedio agregado de la medida

\begin{tabular}{l|l|c|r}
\hline \multicolumn{1}{c|}{ N.o } & \multicolumn{1}{|c|}{ Variable } & $\begin{array}{c}\text { Promedio per } \\
\text { cápita }\end{array}$ & \multicolumn{1}{c}{$\begin{array}{c}\text { Agregado } \\
\text { muestra }\end{array}$} \\
\hline 1 & Ingreso & $\$ 70862011,76$ & 6023271000,00 \\
\hline 2 & Gasto & $\$ 63842622,71$ & 5426622930,00 \\
\hline $3: 1-2$ & Ahorro sin pago de declaración & $\$ 7019389,06$ & 596648070,00 \\
\hline 4 & Pago declaración & $\$ 3880363,64$ & 171088000,00 \\
\hline $5: 1-2-3$ & Ahorro con el pago de la declaración & $\$ 3131025,42$ & 425560070,00 \\
\hline
\end{tabular}

Fuente: elaboración propia con programa Excel.

Los datos de la muestra suponen un ahorro agregado esperado (de los 86 profesionales) por valor de $\$ 596$ millones; la suma de los pagos por concepto de declaración de renta fue de $\$ 171$ millones, luego el ahorro real será de $\$ 425$ millones.

Para observar en la población cual sería un alcance en dinero, si se estima que en Caquetá en 2013 existen cerca de 8822 profesionales con maestría según cifras del Observatorio Nacional para la Educación a 2013; donde en el hipotético de que solo el $51 \%$ deben pagar declaración de renta, esto es 4499 personas, el valor con un promedio de pago de $\$ 3880363$ millones, el recaudo alcanzaría $\$ 17457$ millones de pesos, valor que se le restaría a los beneficios de las empresas de bienes y servicios.

Para citar un ejemplo, se exponen los datos de uno de los encuestados para ver el impacto al interior de dos hogares; no se presentan sus datos personales (Tabla 18). 
142 ACTIVOS | Yelly Yamparli Pardo Rozo, Chris Nathalie Aristizábal Valbuena, Gloria Astrid Duque

Tabla 18. Ejemplo declaración de renta y complementarios en personas naturales año gravable 2017

\begin{tabular}{|c|c|c|c|}
\hline & \multicolumn{2}{|l|}{ NIT: X.XXX.0XX-X } & \\
\hline & \multicolumn{2}{|l|}{ NOMBRE: XXXXX } & \\
\hline & \multicolumn{2}{|c|}{ ACTIVIDAD ECONÓMICA: 00XX } & \\
\hline$\tilde{0}$ & \multicolumn{2}{|c|}{ CÓDIGO DIRECCIÓN SECCIONAL: 28} & \\
\hline 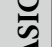 & \multicolumn{2}{|l|}{ PATRIMONIO BRUTO 2016} & 921.767 .000 \\
\hline$\infty$ & \multicolumn{2}{|l|}{ PATRIMONIO LÍQUIDO 2016} & 921.767 .000 \\
\hline 읍 & \multicolumn{2}{|l|}{ VALOR UTV 201629.753} & 29.753 \\
\hline & \multicolumn{2}{|l|}{ VALOR UTV 2017: 31859} & 31.859 \\
\hline \multirow{17}{*}{ 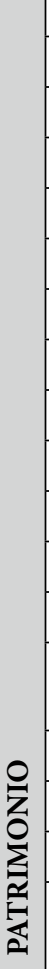 } & \multicolumn{3}{|l|}{ PATRIMONIO BRUTO } \\
\hline & Banco 1. Cuenta de ahorro & 13.646 .000 & \\
\hline & Banco 2. Cuenta corriente & 728.000 & \\
\hline & Banco 3. Cuenta de ahorro & 1.053 .000 & \\
\hline & Cuentas por cobrar a XXXX & 122.019 .000 & \\
\hline & Acciones XXXX & 16.800 .000 & \\
\hline & Vehículo. Camioneta & 33.030 .000 & \\
\hline & Casa 1 & 319.415 .000 & \\
\hline & Casa 2 & 48.121 .000 & \\
\hline & Casa 3 & 50.421 .000 & \\
\hline & Casa 4 & 49.370 .000 & \\
\hline & Casa 5 & 78.901 .000 & \\
\hline & Casa 6 & 34.389 .000 & \\
\hline & $\begin{array}{l}\text { TOTAL PATRIMONIO } \\
\text { BRUTO }\end{array}$ & & 767.893.000 \\
\hline & DEUDAS & & \\
\hline & TOTAL DEUDAS & & - \\
\hline & $\begin{array}{l}\text { TOTAL PATRIMONIO } \\
\text { LIQUIDO }\end{array}$ & & 767.893.000 \\
\hline
\end{tabular}




\begin{tabular}{|c|c|c|c|}
\hline \multirow{15}{*}{ 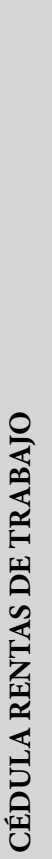 } & Ingresos brutos por rentas de trabajo & & 141.242 .000 \\
\hline & salarios, primas, otras asociadas al contrato $\mathrm{T}$ & 85.620 .000 & \\
\hline & Gastos de representación & 45.398 .000 & \\
\hline & cesantías, intereses/cesantías recibidas & 10.224 .000 & \\
\hline & ingresos no constitutivos de renta & & 9.800 .000 \\
\hline & aportes salud & 4.237 .000 & \\
\hline & aportes pensión & 5.563 .000 & \\
\hline & Renta líquida & & 131.442.000 \\
\hline & $\begin{array}{l}\text { Rentas exentas de trabajo y deducciones } \\
\text { imputables }\end{array}$ & & 74.577 .000 \\
\hline & gastos de representación & 45.398 .000 & \\
\hline & cesantías, intereses/cesantías recibidas & 10.224 .000 & \\
\hline & $25 \%$ ingresos por salarios & 18.955 .000 & \\
\hline & $\begin{array}{l}\text { Rentas exentas de trabajo y deducciones } \\
\text { imputables }\end{array}$ & & 74.577 .000 \\
\hline & $\begin{array}{l}\text { Rentas exentas de trabajo y deducciones } \\
\text { limitada } 40 \%\end{array}$ & & 52.576 .000 \\
\hline & Renta líquida cedular de trabajo & & 78.866 .000 \\
\hline
\end{tabular}

\begin{tabular}{|c|c|c|}
\hline \multicolumn{3}{|c|}{ Ingresos brutos por rentas de pensiones } \\
\hline $\bar{z}$ & ingresos no constitutivos de renta & - \\
\hline 党 & Aporte de salud & \\
\hline 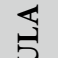 & Rentas exentas de pensiones & - \\
\hline 空 & Renta líquida cedular de pensiones & $\mathbf{0}$ \\
\hline
\end{tabular}


144 ACTIVOS | Yelly Yamparli Pardo Rozo, Chris Nathalie Aristizábal Valbuena, Gloria Astrid Duque

\begin{tabular}{|l|l|r|r}
\hline Ingresos brutos rentas de capital & & 8.160 .000 \\
\hline intereses y rendimientos financieros & 160.000 & \\
\hline Arrendamientos & 8.000 .000 & \\
\hline ingresos no constitutivos de renta & & 103.000 \\
\cline { 2 - 4 } & Costos y gastos procedentes & & 4.040 .000 \\
\cline { 2 - 4 } & impuesto predial casa que generan renta & 2.040 .000 & \\
\cline { 2 - 4 } & Reparaciones locativas de casa que generan renta & 2.000 .000 & \\
\cline { 2 - 4 } & Renta líquida cédula rentas de capital & & 4.017 .000 \\
\cline { 2 - 4 } & Renta líquida ordinaria del ejercicio & & \\
\cline { 2 - 4 } & Renta líquida cedular de capital & & 4.017 .000 \\
\hline
\end{tabular}

\begin{tabular}{|c|c|c|}
\hline \multirow{7}{*}{ 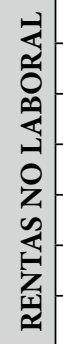 } & Ingresos brutos no laborales & \\
\hline & costos y gastos procedentes & \\
\hline & Renta líquida & \\
\hline & Rentas exentas y deducciones imputable & \\
\hline & Renta líquida ordinaria del ejercicio & \\
\hline & Rentas líquidas gravables no laborales & \\
\hline & Renta líquida cedular no laboral & \\
\hline \multirow{2}{*}{ 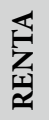 } & Total rentas líquidas cedulares & 82.883 .000 \\
\hline & Renta presuntiva & \\
\hline
\end{tabular}




\begin{tabular}{|c|c|c|}
\hline & Impuesto sobre las rentas: & \\
\hline & De trabajo y de pensiones & 10.613 .000 \\
\hline & De capital y no laboral & \\
\hline & Por dividendos y participaciones & \\
\hline & Total impuesto sobre rentas cedulares & 10.613 .000 \\
\hline & Impuesto sobre renta presuntiva & \\
\hline & Total impuesto sobre la renta líquida & 10.613 .000 \\
\hline & Impuesto neto de renta & 10.613 .000 \\
\hline & impuesto de ganancias ocasionales & \\
\hline & Total impuesto a cargo & 10.613 .000 \\
\hline & Anticipo renta liquidado año anterior & 1.106 .000 \\
\hline $\mathrm{Z}$ & Saldo a favor del año gravable sin solic. & \\
\hline 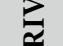 & Retenciones año gravable a declarar & 4.121 .000 \\
\hline$\hat{z}$ & Anticipo renta año siguiente & 1.916 .000 \\
\hline 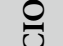 & Saldo a pagar por impuesto & 7.302 .000 \\
\hline á & Sanciones & \\
\hline 5 & Total saldo a pagar & 7.302 .000 \\
\hline ב & Total saldo a favor & \\
\hline
\end{tabular}

Fuente: declaración de renta de un profesional encuestado.

En el ejemplo anterior, se observa que el pago de la declaración fue de \$10 613000 , que con el anticipo le deja un valor de pago final de \$7 302 000. Para este profesional, el pago en el 2017 (correspondiente a 2016) fue por $\$ 3800000$, por lo tanto la reducción del ahorro fue de \$6813000.

\section{Discusión de los resultados}

En Pardo, Peña y Orjuela (2018) se citan los estudios de evidencia empírica del consumo como el de Vargas (2015), quien calcula una PMgC de 8 $5 \%$, esto significa que esto se destina a gastos y el porcentaje restante es el potencial de ahorro; de igual forma los autores citan el estudio de Casas y Gil (2011) quienes estimaron la PMgC en Colombia y hallaron un valor de 0,6 , monto que supone un ahorro de 0,4 . 
Luego, Pardo et al., (2018) encuentran un PMgC en Caquetá de $\$ 0,59$ empleando un modelo lineal simple, con un ahorro del 0,41. Los valores hallados en la presente investigación de 0,90 en la situación inicial, es un valor mucho mayor, lo que indica que en los profesionales encuestados existe una baja cultura de ahorro e inversión. Esto agrava mucho más la problemática frente al pago que no estaba contemplado dentro de los gastos al interior de los hogares.

Al observar el origen del dinero para pagar la declaración de renta del 2017 en el 2018, se afectó el ahorro que estaba destinado para salud (que puede considerarse como un costo porque busca conservar la salud humana); afectó los gastos de recreación y las inversiones en educación y vivienda. Esto impactará indirectamente a las empresas y mercados en que ellas se encuentran, porque se experimentarán reducciones en los consumos en dichos bienes y servicios, lo que afectará al sector productivo.

Según el grupo de estudios fiscales y de equidad y red de justicia de la Universidad Nacional, la clase media ha sido la más afectada con la medida tributaria, pues el sistema tributario colombiano contradice la filosofía de los sistemas tributarios en el mundo, donde países capitalistas basan sus principales características en la eficiencia y progresividad, donde quienes poseen más riqueza e ingresos son los que más impuestos pagan; pero con esta medida los asalariados y profesionales independientes fueron afectados y no los dueños de grandes capitales como el sistema financiero, los grupos económicos y las grandes empresas.

La limitación al 40 \% como tope máximo que estaba exento porque correspondía a vivienda, aportes de salud pensión y personas a cargo, es lo que más afectó a la clase media. Los autores exponen un ejemplo de la situación de los profesores universitarios, uno de los sectores seriamente afectados con la medida, donde se demuestra que el impuesto aumentó en 829 \% lo cual es irracional para una economía en desarrollo como la colombiana; y además mencionan que al analizar las declaraciones de renta de la Dian del 2013, en las que las personas obligadas a llevar contabilidad -quienes reciben siete veces más ingresos- pagaron solo un $0.5 \%$ de sus 
ingresos, en tanto que aquellas que no están obligadas pagaron $3.1 \%$, lo que equivale a unas seis veces más.

Las reformas tributarias deberán garantizar el desarrollo del país, porque a través del recaudo, se debería redistribuir equitativamente la riqueza y el ingreso, dado el supuesto de invertir tales recursos en programas sociales que en esencia son la salud, la educación, la vivienda y el transporte.

Sin embargo, como se mencionó en el componente teórico, los impuestos tienen como función corregir distorsiones del mercado, pero los efectos de un ineficiente sistema tributario no solo genera la concentración de la riqueza, sino que reduce la capacidad de ahorro e inversión y aumenta el endeudamiento lo cual es totalmente contrario al crecimiento y desarrollo económico, y uno de los efectos en el largo plazo es la reducción en los consumos lo que afectará los ingresos del sistema productivo.

Esto es opuesto a lo que los propios planes de Gobierno establecen desde los objetivos de desarrollo sostenible como política mundial que busca reducir la pobreza. A este problema se le suma la ineficiencia y corrupción por parte del Gobierno, lo que no garantiza una reinversión de los dineros del recaudo fiscal. Como lo establece Ladino (2017), estas medidas fiscales derogaron beneficios que los contribuyentes tenían con el sistema IMAS e IMAN, que generaban un menor pago en el impuesto de renta, y a esto se suman los anticipos de retención.

Otro factor a evaluar es qué tanto van a resistir los hogares de clase media en materia de tiempo y dinero con una medida que según este estudio ha implicado el endeudamiento del $47 \%$ de los declarantes; la disminución del ingreso en los hogares, para alivianar el déficit fiscal generará más pobreza en el largo plazo porque los dineros que se trasfieren al sostenimiento fiscal, estaban destinados al consumo de bienes y servicios por lo que se afecta el propio aparato productivo, que luego tendrá que reducir número de empleos y salarios, contribuyendo más a la desigualdad y pobreza. Lo anterior es claro porque no existe cultura de ahorro y menos para pagos de impuestos. 
Según Clavijo (2018), en Colombia el ingreso bruto de los hogares representa cerca del $65 \%$ del PIB real y para medir la capacidad adquisitiva se resta el componente de impuestos directos para hallar el ingreso disponible. En los últimos años estos impuestos pagados por los hogares representaron el $3 \%$ del PIB, lo cual redujo el ingreso disponible de los hogares a $62 \%$, pero teniendo en cuenta que los ingresos de las rentas del capital, que son de $15 \%$ del PIB real, no deben asociarse a los ingresos de la clase media y alta, sino a ingresos de la clase muy alta, se reduce a un $50 \%$.

Sobre el $50 \%$ del PIB real es que se da la discusión sobre cuánto más espacio existe para pensar en gravar a los asalariados. El analista primero aclara que los hogares más pudientes ya enfrentan tasas efectivas de tributación directa históricamente elevadas hasta del $27 \%$ (a nivel de $\$ 100$ millones/mes), según la Ley 1819 del 2016, y establece que el ingreso disponible de los hogares de clase media y alta ya se ve drenado en cerca del $28 \%$ cuando se trata de un empleado y hasta en un $32 \%$ cuando se trata de trabajadores independientes.

Sin embargo, el recaudo en Colombia por impuestos a los hogares continúa siendo bajo y aún no se han visto los beneficios de poner a declarar gente en los estratos medios-bajos. Esto implica que la Administración 2018-2022 deberá recargarse más en ganar eficiencia en el recaudo que en pensar en elevar las tasas marginales o efectivas de los estratos altos-medios.

El autor menciona que en los países emergentes rara vez los pagos a la seguridad social por parte de las empresas o individuos equivalen al "valor de mercado" correspondiente a los servicios de pensiones o salud. A los Gobiernos les gusta utilizar el mecanismo de "contribuciones a la seguridad social" para esconder estructuras de subsidios cruzados.

Esto da origen a lo que se conoce en la literatura como los "impuestos puros" a los estratos medios-altos y, supuestamente, a favor de los estratos bajos. Para el caso de Colombia, es posible demostrar que existe un cuantioso "impuesto puro". 
De otro lado, Ladino (2017) califica como fuertes los impactos en las personas naturales dada la contribución de renta y complementarios de la reforma tributaria estructural de la Ley 1819 del 2016, al derogar beneficios que anteriormente tenían los contribuyentes, y menciona que la limitación dada por el $40 \%$ de las rentas exentas generará poca incentivación para la inversión, debido a que limita la posibilidad de deducción de los aportes voluntarios a fondos AFP y AFC, pues, aun cuando se realicen estos aportes, no se podrán descontar de la renta líquida al momento de presentar la declaración de renta; esto sin dejar de lado el hecho de que ahora retirar dichos ahorros de los fondos también estarán sujetos a retenciones.

\section{Conclusiones}

Se determinaron los efectos en la propensión marginal al consumo en los profesionales de Florencia, Caquetá (Colombia), dado el pago de la declaración de renta año gravable 2017 ante la disminución de las rentas exentas según la Ley 1819 del 2018, encontrándose una disminución de la PMgC por un valor de 0,47 en el corto plazo.

Se conoció la percepción de los profesionales sobre las medidas de política tributaria donde se observó que se afectaron los planes de consumo en recreación y esparcimiento y las inversiones en educación y vivienda; principalmente los costos de la salud.

Se identificó que la actual propensión marginal al consumo en 2017 en profesionales de Florencia, Caquetá, fue de 0,90.

Ante la medida tributaria se encontró que la $\mathrm{PMgC}$ de 0,90 cambia a 0,94 lo que reduce la capacidad de ahorro y su destino en consumos; en la tendencia de generalizarse la medida, se puede llegar a un 0,99 lo que reduce sustancialmente el potencial de ahorro de los hogares en Florencia.

Los profesionales no realizaron una planeación en el pago para la medida tributaria, con lo cual el $47.7 \%$ realizaron prestamos en general de 
libre inversión y uso de tarjetas de crédito para cumplir con el pago, lo cual afecta en el largo plazo el endeudamiento y la capacidad de pago y consumos futuros, por lo que se impacta aún más en la economía de los hogares, lo que se puede considerar como una baja en el salario si se tiene en cuenta que en Colombia el salario mínimo tiene aumentos en el año por debajo del índice de inflación y aumentos que en promedio en los últimos años no superan el $7 \%$, cifra inferior a otros impuestos como el IVA.

Los datos de la muestra suponen un ahorro agregado esperado (de los 86 profesionales) por valor de $\$ 596$ millones; la suma de los pagos por concepto de declaración de renta fue de $\$ 171$ millones, luego el ahorro real será de $\$ 425$ millones, que para el Caquetá se cuantifica en mínimo un recaudo de \$17 457 millones de pesos, valor que se le restaría a los beneficios de las empresas de bienes y servicios. En este punto el impuesto es distorsionante del equilibrio del mercado, pues garantizar que el recaudo se reinvierta en infraestructura tecnológica y para el sistema productivo ante panoramas de alta corrupción es poco factible.

Según los medios de prensa, la declaración y pago del impuesto de renta de las personas naturales deja cifras más satisfactorias de las esperadas, pues el recaudo por este tributo ascendería a $\$ 2.4$ billones, es decir, $\$ 400000$ millones más (20\%) de lo proyectado inicialmente por la Dian; menciona que según la firma Tributar Consultores, los aumentos en el pago real van desde el 30 hasta el $300 \%$ en distintos casos, y responden justamente a los cambios generados por la reforma fiscal de hace dos años.

Se recomienda que próximos estudios en este tema, tengan en cuenta el valor de los intereses generados en el mediano plazo y cuál es el costo de oportunidad de uso del dinero de los mismos. Esto quiere decir, que se pueden calcular los intereses generados por el pago en las personas que emplearon un crédito para pago; y observar a partir de ello, cuáles habrían sido los destinos de estos dineros si la reforma no existiese. También se podrían realizar estudios de largo plazo donde se investigue cuáles fueron los rubros reales a los que se invirtió el recaudo de los pagos de las declaraciones que realizaron los colombianos, o que se dispuso en el pago del 
aparato fiscal. Otro mecanismo para profundizar en los estudios de los impactos de estas medidas tributarias, es realizar análisis comparativos de países latinoamericanos.

\section{Referencias}

Asociación Bancaria y de Entidades Financieras de Colombia - Asobancaria (1999). Diez años de reformas tributarias.

Banco Interamericano de Desarrollo - BID (2016). Ahorrar para desarrollarse, ¿Cómo América Latina pueden ahorrar más y mejor? Recuperado de https://publications.iadb.org/bitstream/handle/11319/7676/Ahorrar-paradesarrollarse-Como-America-Latina-y-el-Caribe-pueden-ahorrar-mas-ymejor-Resumen.pdf?sequence $=3$

Decreto 624. (1989). Presidencia de la República de Colombia. Estatuto Tributario de los Impuestos Administrados por la Dirección General de Impuestos Nacionales. Diario Oficial n. 38.756 de la República de Colombia, Bogotá D. C., Colombia, 30 de marzo de 1989.

Casas, J. A., y Gil, J. M. (2011). Evidencia empírica de la teoría del consumo en Colombia (2000-2010). Apuntes del CENES, 30(52), 59-86.

Clavijo, S. (2018). Ingreso disponible en hogares y el efecto del impuesto puro. Diario La República. Recuperado de https://www.larepublica.co/analisis/ sergio-clavijo-500041/ingreso-disponible-hogares-y-el-efecto-del-impuestopuro- 2600580

Constitución Política de Colombia [Const.]. (1991). 2da Ed. Legis.

Estatuto Tributario. (2018). Libro Legis, Edición 25, Colombia.

González, F., y Calderón, V. (2002). Reforma Tributaria de Colombia durante el siglo XX (II), Boletines de divulgación económica. Dirección de estudios económicos. Departamento Nacional de Planeación. Bogotá. Recuperado de https:// colaboracion.dnp.gov.co/CDT/Estudios\%20Econmicos/Las\%20reformas\%20 tributarias\%20en\%20Colombia\%20durante\%20el\%20siglo\%20XX\%20(II).pdf Gujarati, D., y Porter, D. (2010). Econometría Básica. 5 ed. Bogotá D. C., Colombia: McGraw Hill.

Hernández, R., Fernández, C., \& Baptista, L. (2014). Metodología de la Investigación. Quinta Edición, México D. F., México: McGraw Hill. 
152 ACTIVOS | Yelly Yamparli Pardo Rozo, Chris Nathalie Aristizábal Valbuena, Gloria Astrid Duque

Ladino, L (2017). Qué efectos tiene sobre las personas naturales contribuyentes de renta y complementarios la reforma tributaria estructural Ley 1819 de 2016. Bogotá D. C., Colombia: Universidad Militar Nueva Granada.

Ley 75. (1986). Reforma Tributaria para fortalecer el mercado de capitales y valores. Diario Oficial n. ${ }^{\circ} 37.742$ de la República de Colombia, Bogotá D. C., Colombia, 23 de diciembre de 1986.

Ley 49. (1990). Reglamenta la repatriación de capitales, se estimula el mercado accionario, se expiden normas en materia tributaria, aduanera. Diario Oficial n. 39615 de la República de Colombia, Bogotá D. C., Colombia, 28 de diciembre de 1990.

Ley 6. (1992). Normas Tributarias. Diario Oficial n. ${ }^{\circ} 40.490$ de la República de Colombia, Bogotá D. C., Colombia, 30 de junio de 1992.

Ley 100. (1993). Sistema de Seguridad Social. Diario Oficial n. ${ }^{\circ} 41.148$ de la República de Colombia, Bogotá D. C., Colombia, 23 de diciembre de 1993.

Ley 218. (1995). Por la cual se modifica el Decreto 1264 del 21 de junio de 1994 proferido en desarrollo de la emergencia declarada mediante... Diario Oficial n. ${ }^{\circ} 42.117$ de la República de Colombia, Bogotá D. C., Colombia, 17 de noviembre de 1995.

Ley 223. (1995). Racionalización Tributaria. Diario Oficial n. ${ }^{\circ} 42.160$ de la República de Colombia, Bogotá D. C., Colombia, 20 diciembre de 1995.

Ley 383. (1997). Lucha contra la evasión y el contrabando. Diario Oficial n. ${ }^{\circ} 43.083$ de la República de Colombia, Bogotá D. C., Colombia, 10 de julio de 1997.

Ley 488. (1998). Normas en materia tributaria. Diario Oficial n. ${ }^{\circ} 43.460$ de la República de Colombia, Bogotá D. C., Colombia, 24 de diciembre de 1998.

Ley 1819. (2016). Reforma Tributaria. Diario Oficial n. 50.101 de la República de Colombia, Bogotá D. C., Colombia, 29 de diciembre de 2016.

Pardo, Y.Y., Peña, P., y Orjuela, J. A. (2018). Valoración económica de servicios ambientales en sistemas productivos de Belén de los Andaquíes (tesis de posgrado). Universidad de la Amazonia, Vicerrectoría de Investigaciones y Posgrados, Florencia, Caquetá, Colombia.

Patiño León, E. M., y Torres Caro F. J. (2007). Evolución de los mecanismos de control contra la evasión del impuesto a la renta en Colombia. Comportamiento y resultados observados durante los años 1990 a 2005 (tesis de grado). Universidad de La Salle, Bogotá D. C., Colombia. 
Roca, R. (2008). Teorías del consumo y el ahorro. Macroeconomía Avanzada, Universidad Mayor de San Marcos y Pontificia Universidad Católica del Perú. Recuperado de https://www.researchgate.net/profile/Richard_ Roca/publication/228779336_Teorias_del_Consumo_y_el_Ahorro/ links/54be5a7e0cf218da9391e6c9/Teorias-del-Consumo-y-el-Ahorro.pdf

Steiner, R (1991). La Cuenta Especial de Cambios, las utilidades del Banco de la República y el déficit del sector público, Revista ESPE, (20), 175-189. Recuperado de http://www.banrep.gov.co/sites/default/files/publicaciones/ archivos/espe_020-6.pdf

Taylor, S. J., y Bogdan, R. (1987). Introducción a los métodos cualitativos de investigación. Barcelona, España: Paidós.

Vargas, G. G. (2015). Propensión marginal al consumo para Colombia. [The marginal propensity to consume for Colombia]. Universidad Distrital Francisco José de Caldas. Recuperado de https://www.researchgate.net/ publication/286625971_PROPENSION_MARGINAL_AL_CONSUMO_ PARA_COLOMBIA_The_marginal_propensity_to_consume_for_Colombia. Zamara, F., y Zamara, C. (2017). Reforma Tributaria comentada Ley 1819 de 2016. Bogotá D. C., Colombia: Legis S. A. 